\title{
BMJ Open Employment status and information needs of patients with breast cancer: a multicentre cross-sectional study of first oncology consultations
}

\author{
Maria Angela Mazzi, ${ }^{1}$ Cinzia Perlini (D , , ${ }^{1}$ Giuseppe Deledda, ${ }^{2}$ Alberto Ghilardi, ${ }^{3}$ \\ Chiara Buizza, ${ }^{3}$ Alessandro Bottacini, ${ }^{1}$ Claudia Goss, ${ }^{1}$ Lidia Del Piccolo ${ }^{1}$
}

To cite: Mazzi MA, Perlini C, Deledda G, et al. Employment status and information needs of patients with breast cancer: a multicentre cross-sectional study of first oncology consultations. BMJ Open 2020;10:e038543. doi:10.1136/ bmjopen-2020-038543

- Prepublication history and additional material for this paper is available online. To view these files, please visit the journal online (http://dx.doi.org/10. 1136/bmjopen-2020-038543).

Received 16 March 2020 Revised 26 June 2020 Accepted 14 August 2020

\section{Check for updates}

(c) Author(s) (or their employer(s)) 2020. Re-use permitted under CC BY-NC. No commercial re-use. See rights and permissions. Published by BMJ.

${ }^{1}$ Department of Neurosciences, Biomedicine and Movement Sciences, Section of Clinical Psychology, University of Verona, Verona, Italy

${ }^{2}$ Clinical Psychological Service UO of Clinical Psychology, Scientific Institute for Research, Hospitalisation and Health Care (IRCCS) "Sacro Cuore - Don Calabria", Negrar di Valpolicella, Verona, Italy

${ }^{3}$ Department of Clinical and Experimental Sciences, Unit of Clinical Psychology, University of Brescia, Brescia, Italy

Correspondence to

Dr Cinzia Perlini;

cinzia.perlini@univr.it

\section{ABSTRACT}

Objectives To investigate the early information needs of women with a recent diagnosis of breast cancer (BC) according to their employment status.

Design Cross-sectional.

Setting Secondary-care patients attending three outpatient oncology clinics in northern Italy.

Participants 377 women with a recent diagnosis of earlystage, non-metastatic BC aged 18-75 were recruited. Of them, 164 were employed, 103 non-employed and 110 retired.

Outcome measures The first consultation visit with an oncologist was audio-recorded and analysed for the number and type of questions asked. Linear regression models considering consultations' and patients' characteristics as confounding variables were applied. Results Employed patients asked significantly more questions than non-employed and retired patients (17 vs 13 and $14 ; F=6.04 ; p<0.01)$. When age and education were included in the statistical model, the significance of employment status was rearranged among all the variables and was no more significant $(b=1.2, p=0.44)$. Employed women asked more questions concerning disease prognosis ( 0.7 vs 0.4 and $0.6 ; F=3.5 ; p=0.03$ ), prevention ( 1.4 vs 0.6 and $0.7 ; F=10.7 ; p<0.01$ ), illness management ( 7.2 vs 6 and $5.4 ; \mathrm{F}=3.8 ; \mathrm{p}=0.02)$ and social functioning ( $37 \%$ vs $18 \%$ and $20 \% ; \chi^{2}=14.3$; $\mathrm{p}<0.01)$ compared with the other two groups. Finally, they attended more frequently the consultation alone ( $37 \%$ vs $18 \%$ and $25 \% ; \chi^{2}=10.90, p<0.01$ ), were younger (50 vs 58 and 67 years; $F=63.8 ; p<0.01$ ) and with a higher level of education ( $77 \%$ vs $27 \%$ and $45 \%$; $\chi^{2}=68.2 ; p<0.01$ ).

Conclusions Employment status is related to the type of questions asked during the first consultation. Also, it interrelates with other patients' characteristics like age and education in determining the number of questions asked. Patients' characteristics including employment status could be considered in tailoring work and socialrelated information provided during the first oncological consultation. Future studies could explore potential differences in information needs according to the different kinds of work.
Strengths and limitations of this study

This is the first study in Italy exploring the information needs in a large sample of women with breast cancer with different occupational status at their first consultation visit with the oncologist.

- We included in our analyses all the variables suggested by literature as relevant for the topic (age, education level, cancer stage, presence of a companion, length of consultation, difference in the setting).

- The study's robust methodology and statistical analyses allow for generalising the results to Italian patients living in northern Italy with similar characteristics.

- The main limitation of the study is that it focuses on secondary analysis of two previous studies, therefore we were not able to distinguish between employees and self-employed and to stratify the sample according to the type of employment.

\section{INTRODUCTION}

Breast cancer (BC) is the most commonly diagnosed cancer in women worldwide. ${ }^{1}$ In Italy, the last official report on cancer described $\mathrm{BC}$ as the first cause of death for cancer in women, with 53000 new cases expected in 2019 and an increasing rate $(+0.3 \%)$ of diagnosis. This is possibly due to the extension of screening programmes and a greater incidence in the subpopulation not covered by programmes themselves. The survival rate of BC in Italy is $87 \%$ after 5 years from the diagnosis and $80 \%$ at 10 years. $^{2}$

Although the $\mathrm{BC}$ journey is not uniform for all women, ${ }^{2}$ the BC diagnosis often leaves patients with many questions about what to expect during the long and arduous diagnostic-therapeutic pathway ahead of them. Women are burdened not only by the disease and treatment-related symptoms (pain, 
fatigue, side effects) but also by emotional distress and anxiety about changes in their life. ${ }^{3}$

A major factor that influences patients' emotional state is employment status. Employed women experience greater anxiety before surgery than unemployed women. They worry about how the disease will affect their professional life and whether they will be able to fulfil job requirements at their former places of employment. ${ }^{4}$ Yet, having gainful employment also has a positive influence on the quality of life, ensures financial security, social contacts and a sense of contributing. ${ }^{5-7}$ Moreover, women with cancer who continue working during their course of treatment describe work as a normalising factor in their life $e^{8-12}$ that enables them to cope with the disease better than if they remained alone at home. The interplay between employment and a positive sense of self confers a sense of normalcy that can boost self-esteem during treatments. ${ }^{13}$ By continuing to work, patients project an image of strength and self-competence that helps to allay their fears about a potential loss of income. ${ }^{9}$ This may also hold for older women who choose to continue working beyond the full retirement age according to Italian legislation. ${ }^{14}$

Most of the employees in Italy are insured against a temporary inability to work due to their state of health. In particular, the Italian Institute of Social Security pays for sick leave benefits from the 4th to 180th days of absence from work. During this period, the statutory sick pay amount is, generally, equal to $50 \%-66 \%$ of average daily pay. After the 180 days, employees are at risk of losing their work, although other kinds of support can be applied that is, previous leave not taken or unpaid leave. ${ }^{15}$ Such schema does not cover self-employed, but some forms of financial support are provided also in the case of workers with an atypical employment contract and new self-employed. ${ }^{16}$ Independently from occupational status, the Italian National Healthcare System guarantees patients with all the services included in the Essential Care Levels (ECL) with additional services provided by individual regions that they balance in economic and financial terms. They include hospitalisation and medicines included in a constantly consulted group 'A' prescription drugs list which are provided free of charge. ${ }^{17}$

Despite such forms of support against temporary inability to work due to the state of health and ECL, not all patients benefit from such information at the time of their first oncological consultation. During the visit, clinical oncologists explain at length about how symptoms and treatment side effects will be controlled and dedicate little time to discussing psychosocial matters, ${ }^{18}$ often leaving these concerns unaddressed. For example, the decision whether to continue working during cancer treatment should be discussed with the patient's oncologist, but previous studies on cancer survivors reported that most patients do not discuss work issues with their doctors $^{1920}$ and that they had received little advice from healthcare providers. ${ }^{9}$ Employed patients are known to be more motivated to ask their doctors factual questions than retirees or students. ${ }^{21}$ Moreover, taking the opportunity to discuss possible changes in social functioning (ie, work, social and spare time activities) may be a useful way to identify current functional status, performance, or the level of support or care received. ${ }^{22}$ Anticipating these needs is important since social functioning defines how individuals interact with their environment and the ability to fulfil their role at work, in social activities and relationships with partners and family.

To date, most of the literature has examined the impact of BC on work and psychosocial dimension in employed people. In particular, several studies investigated the role of $\mathrm{BC}$ in the working environment after the patient's return to work. ${ }^{9} 192023-30$ Other research showed the importance of encounters promoting the return to work in the first year after BC surgery in reducing sickness absence during the second year after surgery in employed women. ${ }^{31-33}$ Furthermore, a recent study ${ }^{34}$ described a change over time on information needs in BC working survivors in Japan, with treatment-related information ranking highly at the time of diagnosis and the need for more individually tailored information and support on work after the beginning of the treatment. Despite that, only one pilot study has investigated the difference in information needs in patients with BC with different occupational status so far. ${ }^{35}$ Such a study involved 28 patients with $\mathrm{BC}$ receiving outpatient chemotherapy. Different concerns emerged according to the employment status, with employed people showing greater worries about the disease, the ability to work and death compared with the unemployed group. Such differences suggest the importance of identifying distinctions in information needs among different groups of patients to provide a tailored support system in healthcare settings. To the best of our knowledge, our study is the first in Italy exploring information needs in patients with different occupational status at the beginning of their therapeutic pathway.

Given the impact of employment status not only on the economic matter but also on patients' psychosocial dimension, we argue that women with BC, with different occupational status, may have different information needs concerning illness and psychosocial matters (ie, work, social and spare time activities) in the first phases of their therapeutic process. Information needs refer to all questions formulated and answers sought to find a solution for a particular problem. ${ }^{36}$ In this framework, the number and type of questions asked during the first consultation visit are considered an expression of the most immediate information needs and the first indicator of active participation in the consultation visit with a healthcare provider. ${ }^{37}$ In the present study, we, therefore, want to:

1. Explore information needs in three groups of women with different employment status (employed, nonemployed and retired) during their first oncological consultation.

2. Explore which questions about social functioning were selected from a Question Prompt Sheet (QPS) provided to a subgroup of patients before the visit, according to the employment status. 
To accomplish our aims, we analysed audio-recorded first consultation visits in a large sample of patients with $\mathrm{BC}$ with a recent diagnosis of early-stage, non-metastatic $\mathrm{BC}$ who were attending three outpatient oncology clinics in northern Italy between 2010 and 2013.

\section{METHODS}

\section{Sample}

The sample was composed of patients participating in two previous studies. ${ }^{38-40}$ The first ${ }^{38}$ is an observational pilot study for the set-up of the second one ${ }^{3940}$ which is a randomised controlled trial (RCT; ClinicalTrials. gov NCT01510964). Patients of the observational study were recruited during the first 6 months of 2010 in the outpatient clinic of the Medical Oncology Unit of the Hospital Trust of Verona (centre 1), whereas patients of the RCT were enrolled between June 2011 and May 2013 at centre 1 and in other two centres (Clinical Unit of Oncology at the Hospital Trust of Brescia, centre 2; and University Hospital of Verona, centre 3) (see the flow chart describing the sampling procedure in the online supplemental file 1). Both observational and RCT studies were focused on patients' information needs during first oncological consultation, with RCT comparing the effect of a prepared list of evidence-based questions (QPS) and a patient self-generated list of questions (Question ListQL) they would have liked to ask during their consultation. In putting the samples from the observational and the RCT together, we initially verified that the original samples were comparable in terms of clinical and sociodemographic variables including employment status (see online supplemental file 2).

Both observational and RCT protocols were approved by the ethics committees of the respective centres.

Inclusion and exclusion criteria were the same for both studies. In particular, inclusion criteria were: age between 18 and 75 years, a recent diagnosis of early-stage $\mathrm{BC}$ and a first consultation visit with an oncologist. Eligible patients had already undergone breast surgery (eg, lumpectomy). Exclusion criteria were diagnosis of metastasis, disease relapse, cognitive impairments and inability to understand Italian.

The clinical oncologists involved in the study worked at the oncology clinics of the study centres and provided written informed consent to participate in the study.

\section{Employment status}

Subjects were categorised as 'employed' (ie, being employed or self-employed, regardless of job type and the number of working hours), 'non-employed' (ie, being unemployed, a homemaker or a student) or 'retired', according to self-reported occupational status. We decide not to classify patients on working or retirement-age basis since the retirement legislation changed several times over the past years in Italy. ${ }^{14}$ It allowed the existence of different profiles of retired people based on age and/or years of contribution. Moreover, according to the Italian law concerning retirement in force between 1973 and 1995, some public workers retired from work under the age of 40 . Finally, people over 60 can continue working depending on their will, with some distinction between the public and private employment fields.

\section{Procedure}

Patients came to the consultation by appointment, which was scheduled every $45 \mathrm{~min}$. All patients coming to the consultation were considered eligible for the study. They were approached in the clinic waiting room by the oncology nurse who briefly described the study goals and elicited the patient's interest in participating. Interested patients were accompanied to a dedicated room and were given detailed information by the research assistant. Willing patients satisfying inclusion criteria were enrolled and requested to provide written informed consent to participate and have their consultation visit audiorecorded. Sociodemographic data, including age, education level, marital and employment status were collected via a self-report questionnaire.

The visits were conducted according to the standard of usual clinical care at each centre. The oncologists were blind to the patients using the QPS or QL. All consultations were audio-recorded for analysis. The recording device was operated by the oncologist and collected at the end of the day by the researcher.

\section{Analysis of asked questions}

The number and type of questions asked by patients and the duration of the consultation visit were gleaned from analysis of the audio recordings. Questions were defined as 'utterances in interrogative form that ask for information or clarification,. ${ }^{41}$ A codebook and coding procedures for classifying questions by topic were developed to provide uniform definitions, examples and decision rules. Direct questions by patients were identified and transcribed verbatim.

All questions were subgrouped into five main categories used in the literature. ${ }^{43} \mathrm{~A}$ sixth category was 'administrative questions'. The categories were described in box 1. Coding was performed by three of the authors $(\mathrm{GD}, \mathrm{AB}$ and $\mathrm{CB})$. Inter-rater reliability among the three coders was assessed based on the recording of 10 consultation visits (Agreement 62.9\%; Cohen's kappa 0.49). ${ }^{38}$

Box 1 Main categories used to classify questions asked during the consultation

Symptoms (eg, Why is everything so hard around the wound?)

Aetiology (eg, Was it caused by the pill?)

- Prognosis (eg, How likely is it that cancer will spread to other parts of my body?)

Prevention (eg, Is screening every 2 years enough?)

- IIIness management (eg, According to you, is it better to start immediately?)

- Administrative questions (eg, What is the procedure? Do I have to book the next appointment?) 
Box 2 Categories used to classify questions related to the psychosocial dimension

Rights and privileges: questions about payment exemptions, disability benefits or medical certificates.

- Therapy heaviness: questions about the impact of treatment side effects on work.

- Loss of work ability: questions about the ability to maintain the prior level of work performance.

- Other social activities: questions not strictly related to paid work, such as housework, sports and leisure activities.

Questions related to the psychosocial dimension (covering aspects of life possibly affected by the illness like work, personal finances, and social and spare time activities) were recoded in four categories for this study. ${ }^{22}$ Categories are listed in box 2.

Similar categories of questions were searched for in the QPS list offered before the consultation to a subgroup of 158 patients. Selected questions were reported in box 3 .

\section{Data analysis}

Descriptive statistics for demographic and clinical characteristics are expressed as the mean (M) and SD for numerical variables and percentage distribution for categorical variables. One-way analysis of variance and $\chi^{2}$ tests were performed, where appropriate, to explore the differences among centres and patients with different employment status.

The effect of the hierarchical structure of the dataset on the interest variable (ie, number of questions) was checked by using the intraclass correlation coefficient (ICC), as a measure of centres variation; then a multilevel approach was carried out since the ICC value was relevant $(>5 \%)$.

A set of multilevel linear regression models was preliminarily performed to explore the relationship between the number of questions asked and specific consultations' and patients' characteristics. The effect of confounders, ${ }^{40}$ such as consultation length and presence of companions, was estimated (model A); employment status, age, education level, marital status and cancer stage were explored with a series of models B (B1-B5, respectively). The significant variables were included in the final model (model C).

\section{Box 3 Questions selected from the Question Prompt} Sheet list

Do I have to change my diet, my work and my sports activities?

- How will my job be influenced?

- How will my lifestyle be influenced (eg, daily work, daily activities, sexual function)?

- What will be the costs throughout my treatment (eg, medications, chemotherapy, radiotherapy)?

Am I eligible for any compensation benefits if I cannot work?
Collinearity between explanatory variables was checked, using correlation matrices between variables and between estimated coefficients (post-estimation statistics of model C), respectively. High correlation values (greater than \pm 0.90 ) indicated the presence of multicollinearity. ${ }^{44}$

All statistical analyses were performed using Stata statistical software V.15 (StataCorp, College Station, Texas, USA). ${ }^{45}$ The Strengthening the Reporting of Observational Studies in Epidemiology guidelines and checklist for cross-sectional studies ${ }^{46}$ were used.

\section{Patient and public involvement}

Patients were not involved in the development of the research question and outcome measures, study design, or conduct of this study.

\section{RESULTS}

In the following paragraphs, we first reported patients' characteristics, followed by the comparison among the centres. Subsequently, we described results obtained using a series of statistical models and related to the number of questions asked. Finally, we reported results referred to the type of questions asked by women with BC during the first consultation.

\section{Patient characteristics}

A total of 377 Italian-speaking patients took part in the present study. Of them, 164 were employed, 103 were non-employed (94 housewives, 8 non-employed looking for a job and 1 student) and 110 were retired.

According to the TNM classification of the American Joint Committee on Cancer, ${ }^{47} 26 \%$ of patients had cancer at stage $0,45 \%$ at stage I, $21 \%$ at stage II and $8 \%$ at stage III. Cancer stages differed by employment status $\left(\chi^{2}=13.3\right.$, $\mathrm{p}<0.04$ ) (see table 1 ).

As for the presence of a companion, 270 patients $(56 \%$ of the sample) came to the consultation visit with at least one accompanying person, and 107 patients came alone $(44 \%)$. Employed patients more frequently came alone $(37 \%)$ compared with non-employed $(18 \%)$ and retired $(25 \%)$. This difference was statistically significant $\left(\chi^{2}=10.90, \mathrm{p}<0.01\right)$.

Table 1 presents the demographic and clinical characteristics of patients.

A difference in the consultation length was observed between women with high and low educational level (48 vs $44 \mathrm{~min} ; \mathrm{t}=-2.19 ; \mathrm{p}=0.03)$ and different stage of the illness $(40,46,54$ and $53 \mathrm{~min}$, from stage 0 to stage III; $\mathrm{F}=8.58 ; \mathrm{p}=0.01$ ), with patients with higher education level and at cancer stages II and III having longer consultations compared with those with lower education level and less severe disease. By contrast, we did not observe differences in the consultation length by employment status $(47,45$ and 45, respectively for employed, non-employed and retired patients; $\mathrm{F}=0.67 ; \mathrm{p}=0.51$ ).

\section{Comparison among centres}

Of the 377 patients, 70 came from the observational study $^{38}$ and 307 from the RCT study ${ }^{39}{ }^{40}: 100$ came from 
Table 1 Sociodemographic and clinical characteristics of the three groups

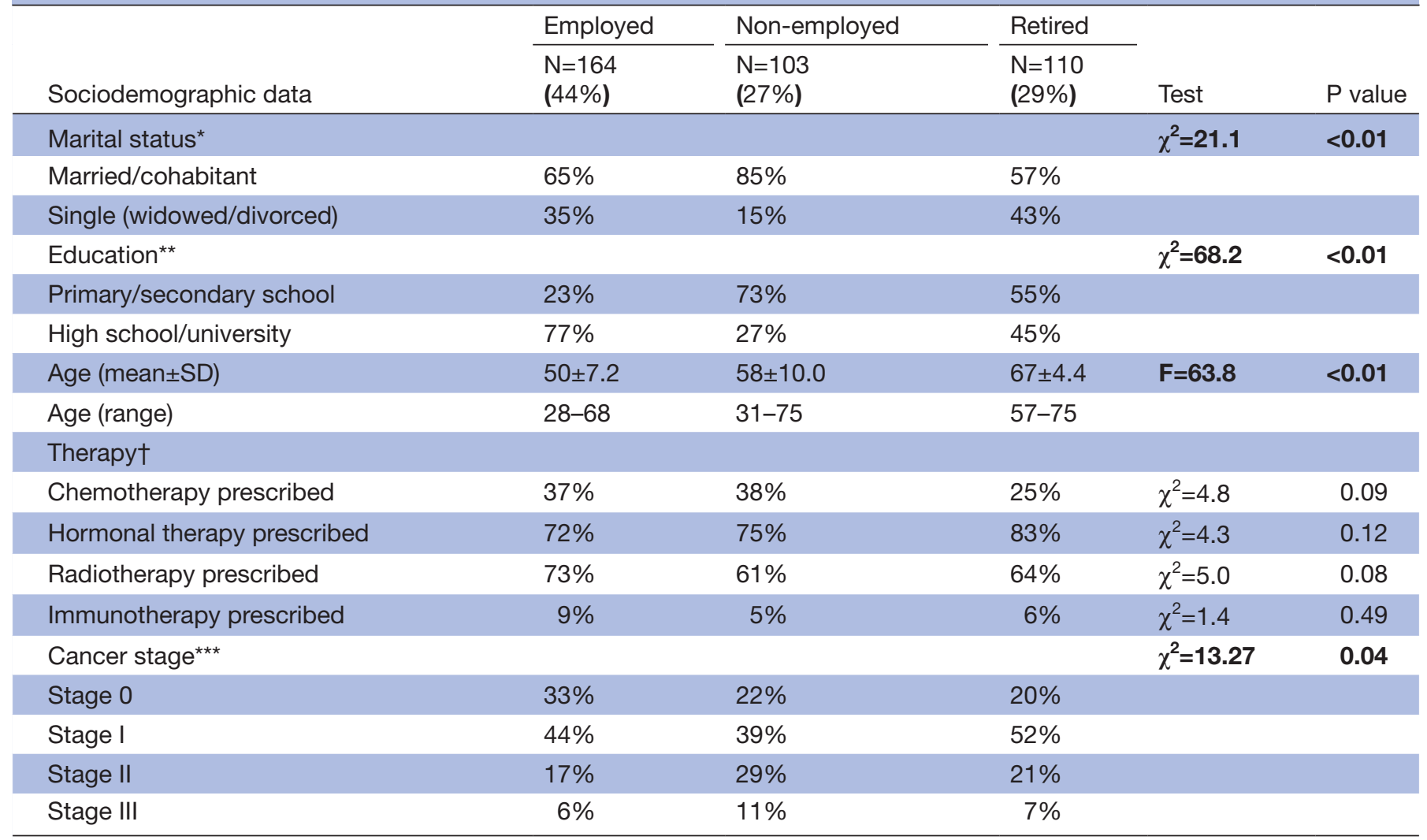

*Significant parameters are written in bold: two missing info, **three missing info, ${ }^{\star \star *} 22$ missing info.

†More than one therapy could be prescribed to each patient.

centre 1, 100 from centre 2, 107 from centre 3. Due to the multicentric design of the study, we tested the existence of differences among groups coming from different centres. The frequency distribution of each subsample showed homogeneous trends, and the applied comparison tests confirmed that there were no relevant differences between the subsamples in sociodemographic variables. All subsamples were homogeneous for employment status (range, $40 \%-46 \%, \chi^{2}=1.10 ; \mathrm{p}=0.77$ ), the presence of companions $\left(\chi^{2}=0.96 ; \mathrm{p}=0.26\right)$ and refusal rate $\left(\chi^{2}=1.78 ; \mathrm{p}=0.62\right)$. A difference among centres was observed on cancer stages $\left(\chi^{2}=21.81 ; \mathrm{p}=0.01\right)$ (see online supplemental file 2).

As regards the characteristics of the consultation, the visit lasted $46 \mathrm{~min}$ on average $(\mathrm{SD}=19.0$; range, 12-111) for the entire sample. A marked difference was observed between the four subsamples $(\mathrm{F}=42.58 ; \mathrm{p}<0.01)$ : mean duration of $35 \mathrm{~min}$ for centre 1 (observational), $38 \mathrm{~min}$ for centre 1 (experimental), $45 \mathrm{~min}$ for centre 2 and 62 min for centre 3 .

\section{Information needs}

Number of questions asked

During their first consultation visit with the oncologist, patients expressed a mean of 15 questions $(\mathrm{SD}=11)$. The employed patients asked, on average more questions $(\mathrm{M}=17, \mathrm{SD}=12)$ than the non-employed or retired patients ( $\mathrm{M}=13, \mathrm{SD}=10$, and $\mathrm{M}=14, \mathrm{SD}=10$, respectively); the difference was significant at the preliminary comparison test $(\mathrm{F}=6.04 ; \mathrm{p}<0.01)$.

Initial exploration of the sample design effect on the number of questions showed an ICC of 5.7, meaning that a part of the variance was due to differences in the four subsamples.

In the first linear regression model (model A), the presence of a companion $(b=-5.1, p<0.01)$ and consultation length $(b=0.3, p<0.01)$ were considered as confounders and were taken into account in the model (table 2). A set of preliminary explorations of the number of questions showed that they were differently distributed in relation to employment status (model $\mathrm{B} 1 ; \mathrm{b}=3.0 ; \mathrm{p}<0.01$ ), age (model B2; $\mathrm{b}=-0.1, \mathrm{p}<0.01)$ and education level (model $\mathrm{B} 3 ; \mathrm{b}=2.2, \mathrm{p}=0.03$ ). Marital status and cancer stage were not significant (model $\mathrm{B} 4 ; \mathrm{b}=-1.4, \mathrm{p}=0.18$; and model $\mathrm{B} 5$; stage I: $b=1.9, p=0.13$; stage II: $b=-0.5, p=0.74$; stage III: $\mathrm{b}=2, \mathrm{p}=0.33$ ) (table 2).

A third model (model C) was estimated after adjusting for these characteristics. In this final model, the statistical significance of occupational status was redistributed among the other patient characteristics and resulted not statistically significant $(b=1.2, p=0.44)$ along with age $(b=-0.1, p=0.16)$ and education level $(b=1.2, p=0.27)$ (table 3). Diagnostic post-regression suggested no 


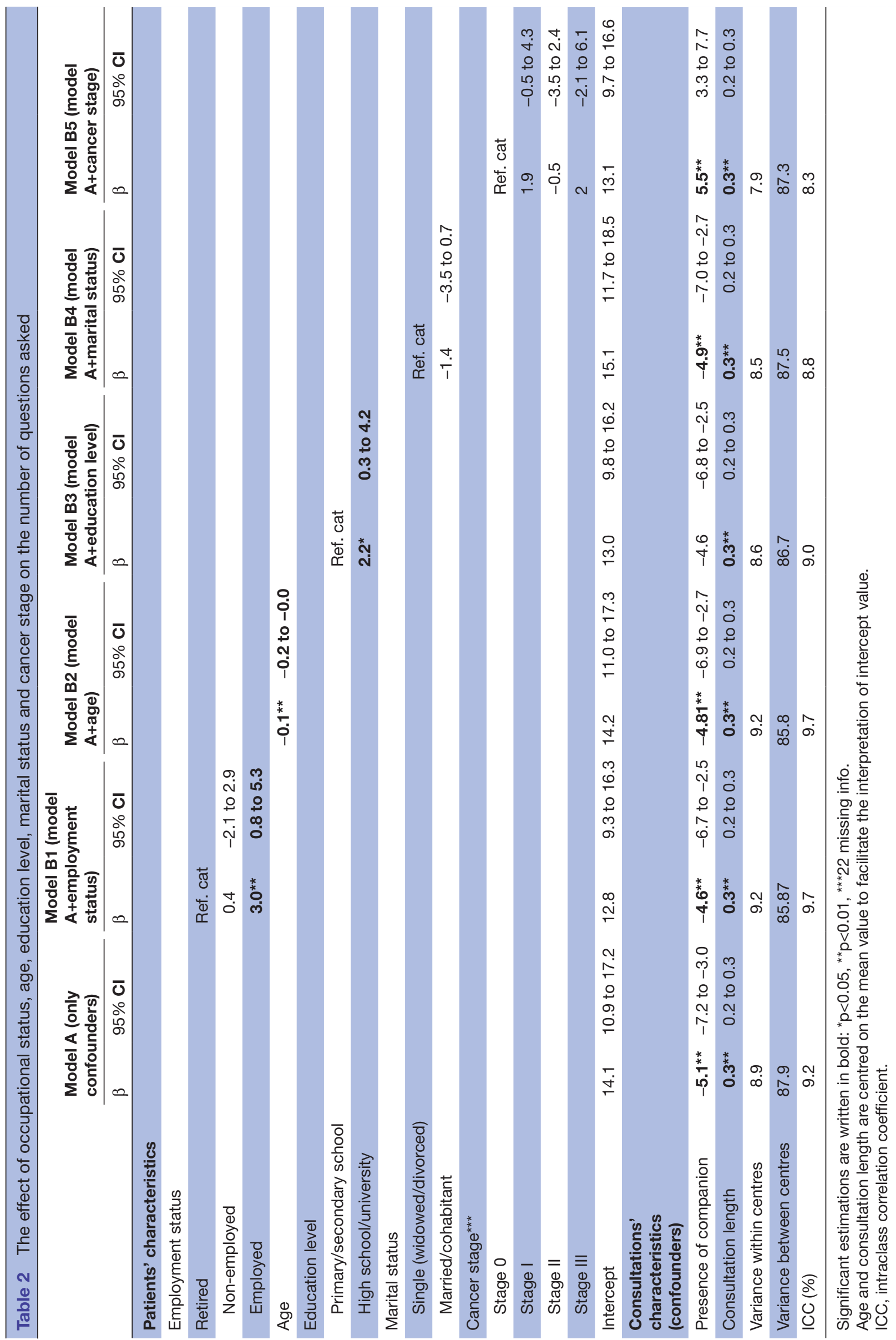


Table 3 The effect of occupational status on the number of questions asked, taking into account patients' characteristics and confounders (final model C)

\begin{tabular}{ll} 
Model C & \\
\hline $\boldsymbol{\beta}$ & $95 \% \mathbf{C l}$ \\
\hline
\end{tabular}

\begin{tabular}{|c|c|c|}
\hline \multicolumn{3}{|l|}{ Patients' characteristics } \\
\hline \multicolumn{3}{|l|}{ Employment status } \\
\hline Retired & \multicolumn{2}{|c|}{ Ref. cat } \\
\hline Non-employed & -0.2 & -3.0 to 2.6 \\
\hline Employed & 1.2 & -1.9 to 4.3 \\
\hline Age & -0.1 & -0.2 to 0.0 \\
\hline Education level & 1.2 & -0.9 to 3.3 \\
\hline Intercept & 13.1 & 9.3 to 17.0 \\
\hline \multicolumn{3}{|c|}{ Consultations' characteristics } \\
\hline Presence of companion & $-4.4^{\star}$ & -6.5 to -2.3 \\
\hline Consultation length & $0.3^{*}$ & 0.2 to 0.3 \\
\hline Variance within centres & 9.1 & \\
\hline Variance between centres & 85.1 & \\
\hline ICC & $9.6 \%$ & \\
\hline
\end{tabular}

Significant estimations are written in bold: ${ }^{*} p<0.01$.

Age and consultation length are based on the mean value to facilitate the interpretation of intercept value.

ICC, intraclass correlation coefficient.

collinearity effect: the correlation matrix showed low to moderate values between employment status and education level $(\mathrm{r}=0.40)$, and between employment status and age $(r=-0.60)$. The values were the same for the correlation coefficients of the last model.

\section{Type of questions asked}

Overall, most of the questions were related to illness management and administrative issues (75\%). Employed patients asked significantly more questions than nonemployed or retired patients about prognosis $(\mathrm{F}=3.5$; $\mathrm{p}=0.03)$, prevention $(\mathrm{F}=10.7 ; \mathrm{p}<0.01)$ and illness management $(\mathrm{F}=3.8 ; \mathrm{p}=0.02)$ (table 4$)$.
Of the total of 377 patients, 101 patients (27\%) asked at least one question about social functioning ( $37 \%$ vs $18 \%$ vs $20 \%$ for employed, non-employed and retired patients, respectively) (table 5). The difference between the three groups was statistically significant $\left(\chi^{2}=14.3 ; \mathrm{p}<0.01\right)$. Concerning the type of questions, $33 \%$ were related to other social activities, $31 \%$ focused on the loss of work ability, $24 \%$ concerned rights and privileges, and only $12 \%$ to therapy heaviness, with a different distribution among groups $\left(\chi^{2}=45.0 ; \mathrm{p}<0.01\right)$. In particular, employed women were more interested in therapy heaviness and loss of work ability; nonemployed people on rights and privileges; and retired people on social activities. Due to the number of cells with frequency $<5$, such finding has to be considered as preliminary.

The two questions 'How will my job be influenced?' and 'Am I eligible for any compensation benefits if I cannot work?' were selected from the QPS of the experimental subgroup $(\mathrm{N}=158)$ significantly more often by the employed patients compared with non-employed and retired patients. Specifically, the question 'How will my job be influenced?' was selected by $31 \%$ of the employed patients, $14 \%$ by the non-employed and $16 \%$ by the retired $\left(\chi^{2}=6.2 ; \mathrm{p}<0.05\right)$. The question 'Am I eligible for any compensation benefits if I cannot work?' was selected by $43 \%$ of the employed patients, $20 \%$ of the non-employed and $5 \%$ of the retired, with a significant difference between the groups $\left(\chi^{2}=19 ; \mathrm{p}<0.01\right)$.

\section{DISCUSSION}

In the present study, we explored for the first time in Italy the information needs expressed by a large group of Italian patients with $\mathrm{BC}$ at their first consultation visit with the oncologist. In particular, we were interested in the potential differences in information needs among patients with different occupational status (employed, non-employed, retired from work) at the beginning of their therapeutic pathway. The number and type of questions asked were considered as expressions of information needs.

Table 4 Information needs of employed, non-employed and retired patients (mean \pm SD)

\begin{tabular}{lcccrl}
\hline Questions & $\begin{array}{l}\text { Employed } \\
(\mathbf{N}=\mathbf{1 6 4})\end{array}$ & $\begin{array}{l}\text { Non-employed } \\
(\mathbf{N = 1 0 3 )}\end{array}$ & $\begin{array}{l}\text { Retired } \\
\mathbf{( N = 1 1 0 )}\end{array}$ & F-test & P value \\
\hline Symptoms & $2.4 \pm 2.8$ & $1.9 \pm 2.0$ & $1.8 \pm 2.4$ & 2.0 & 0.14 \\
\hline Aetiology & $0.3 \pm 0.9$ & $0.2 \pm 0.5$ & $0.2 \pm 0.5$ & 1.6 & 0.20 \\
\hline Prognosis & $0.7 \pm 1.2$ & $0.4 \pm 0.8$ & $0.6 \pm 1.1$ & 3.5 & $\mathbf{0 . 0 3}$ \\
Prevention & $1.4 \pm 1.8$ & $0.6 \pm 1.0$ & $0.7 \pm 1.4$ & 10.7 & $<0.01$ \\
Illness management & $7.2 \pm 6.0$ & $6.0 \pm 5.4$ & $5.4 \pm 4.5$ & 3.8 & $\mathbf{0 . 0 2}$ \\
\hline Administrative & $5.4 \pm 4.0$ & $4.4 \pm 3.5$ & $4.8 \pm 4.2$ & 2.3 & 0.10 \\
\hline
\end{tabular}

Significant $p$ values are written in bold. 
Table 5 Examples of questions asked by patients about social dimensions

\begin{tabular}{ll}
\hline Categories & Questions \\
\hline Rights and privileges & I am a housewife, will I have to pay all of these tests? \\
& Doctor, am I eligible to have any compensation benefit or civil disability? \\
Tho makes the medical certificate?
\end{tabular}

Our data initially showed that the employed patients were more active in expressing their needs with respect to the other two groups, as emerged by the greater number of questions they asked during the consultation. Consistent with previous findings, ${ }^{38}{ }^{48-50}$ in our sample the employed patients were significantly younger and had a higher education level, compared with the other groups. In the regression model, the significance of employment status was indeed redistributed among the other patients' characteristics (age, education level), suggesting that these three variables are closely linked and interrelate with each other. The first clinical implication of these findings is that at the first encounter with the oncologist we can outline different patients' profiles. For example, based on our model we expect that younger, single, employed women with higher education may be more active in the consultation and more demanding about obtaining factual information than women with other sociodemographic conditions.

Our preliminary analyses ${ }^{40}$ showed consultation length and the presence of a companion as impacting on the number of questions asked. Specifically, the longer is the encounter with the oncologist the higher is the number of questions asked. It has been observed that consultations by the Italian oncologists are usually slightly longer than those by oncologists from other Western medical cultures (49 in Italy compared with 30-39 min reported in other countries). ${ }^{40}$ The oncologist's style (and, for extension, setting) can play a role in determining the time of consultation. We indeed observed a difference among centres in consultation time. Other variables potentially affecting visit length are the educational level and the stage of cancer. To control for these variables, we included the consultation length in the statistical model as a confounder, along with the variance among centres (settings), educational level, age and cancer stage (see tables 2 and 3 ). In this way, we have taken into account their weight on our main outcome (number of questions asked). Moreover, being accompanied reduced the number of questions asked. Whereas the first finding is quite intuitive, previous studies suggested that, during a medical consultation, the role of companions varies according to age, education and clinical context, with high companion attendance during oncological examination. ${ }^{5152}$ The level of patient involvement in asking questions and decision-making can, therefore, be affected by such variable. This is especially true in the context of life-limiting cancer diagnosis ${ }^{53}$ or during genetic consultations for inherited $\mathrm{BC}$ where companions may be at risk of developing the same genetic condition as the patient. ${ }^{54}$ Since the presence of a companion did not represent the focus of the present study, we decided to include it in our statistical model as a confounding variable together with consultation length.

As concerns the kind of questions asked, employed patients were more interested in information related to disease prognosis, prevention and illness management compared with non-employed and retired patients. These findings suggest that employed patients consistently want to know how their cancer may evolve and how to keep healthy and active during the course of treatment and beyond. Furthermore, the majority of patients who asked at least one question about psychosocial matters were employed. Regardless of employment status, most questions revolved around routine housework, hobbies, sport and other leisure activities not strictly related to paid work (other social activities). It is within this sphere that patients perceive the need to feel they are capable and resourceful. Patients were also worried about possible changes in their ability to remain active in maintaining their current lifestyle, as demonstrated by the second category of most frequently asked questions: loss of work ability. Work ability has been defined by Lindbohm et a ${ }^{55}$ as a health-related issue associated with working life and society. Its multiple dimensions consist of the resources of the individual, factors related to work and the environment outside of work. When offering advice, oncologists will need to consider the importance that social activities hold for the daily life of their patients. Of note, some differences emerged among the three groups concerning the topic of the questions asked, with employed women being more focused on therapy heaviness and loss of 
work ability; non-employed people on rights and privileges; and retired people on social activities. Although to be considered as preliminary data, it will be of interest to investigate such peculiarities in larger samples.

Besides, work-related questions were selected from the QPS before the oncology consultation visit, not in response to the therapeutic options the oncologists proposed, demonstrating that they were distinctive needs of patients with BC. Previous studies have emphasised that cancer survivors perceive returning to work as a milestone in their journey through cancer. ${ }^{9} 192023-3056$ We found that employed patients are worried about keeping their jobs during cancer therapy and particularly about how the disease and treatments will affect their work ability, and whether they are eligible for compensation of benefits if they cannot return to work. A second clinical implication of our findings is indeed that employment status is an important factor to focus on, already at the first consultation visit, and not only at the end of the therapeutic path when patients are about to face the return to work.

Interestingly, we found no differences between the group of retired and non-employed, neither in the number nor in the kind of questions asked. This is at least partly counterintuitive since we would have expected that non-employed people were more interested at least in work-related issues being them younger than retired women and without income. A realist although speculative explanation is that most of the non-employed women are married or cohabiting, making them scarcely worried about financial issues due to husbands' incomes.

Support systems for people with BC with a focus on psychosocial and work-related issues are jeopardised in different countries. As an example, a recent study by Söderman et $a l^{33}$ showed that $80 \%$ of a 690 Swedish women cohort sample experienced encounters regarding work during the first year after BC surgery. By contrast, the study by Takahashi $e t a l^{34}$ underlined how healthcare systems for working survivors to BC are underdeveloped in Japan, with only $23.5 \%$ of participants screened about work-related issues by a healthcare provider. As regards the Italian context, a previous study by our group ${ }^{57}$ used the Verona Patient-centred Communication Evaluation (VR-COPE) Scale ${ }^{58}$ to rate oncologists' interaction skills on the 308 patients with $\mathrm{BC}$ recruited in the previous RCT study. ${ }^{39} 40$ The VR-COPE consists of nine items, operationally defined and rated on a scale from 0 (no attempt) to 10 (accomplished). It assesses the content, process and relational aspects of patient-centred communication during medical consultations based on a multidimensional evaluation of the physician's communication skills. Interestingly, the VR-COPE score related to the evaluation of the psychosocial impact of illness by the oncologist was very low (a mean of 1.76 on a $0-10$ range). This finding is complementary to what reported by another study carried out in Italy in $2015 .{ }^{59}$ Such a study confirms a general improvement in the amount of information patients with cancer receive from their physicians concerning diagnosis and prognosis, with $84 \%$ of Italian patients being nowadays aware of their diagnosis. Despite that, the study showed that the greater awareness about diagnosis and prognosis was not associated with patients' satisfaction with care and information, suggesting the existence of other kinds of information that possibly remain unmet over time. ${ }^{60}$ Despite specificities due to the context, patients with $\mathrm{BC}$ commonly receive little advice from healthcare providers about work-related and socialrelated issues, and do not talk with their physicians about the implications of cancer and its treatment for their ability to work or to maintain the previous lifestyle ${ }^{1920}$; also, doctors find it difficult to give individual advice. ${ }^{51}$ Overall, such findings underline the need for healthcare providers to explore all the dimensions of the patient's agenda: fears, interpretations, expectations and context. The context dimension (family, social life, work) is indeed a very important component of the patient's illness, influencing how the patient reacts to the disease and copes with it. ${ }^{61}$ Knowledge of the context by the oncologist can, therefore, become a fundamental element to promote patient compliance, a satisfactory clinical relationship and, above all, quality of care ${ }^{62}$ For this reason, workrelated and psychosocial-related issues should be already debated in the very first phase of the therapeutic pathway, when the oncologist should take into account patients' characteristics like employment status, age and education level, in order to facilitate a patient-centred approach aiming at tailoring the intervention on patient's needs.

\section{The present study has strengths and limitations}

As for strengths, this is the first study in Italy exploring information needs of patients with $\mathrm{BC}$ according to employment status in a relatively large sample, with a reasonably low refusal rate. Moreover, we included in our analyses all the variables suggested by literature as relevant for the topic (age, education level, cancer stage, presence of a companion, length of consultation) or on the basis of our study design (setting). Indeed, the study's robust methodology and statistical analyses allow for generalising the results to patients living in northern Italy with similar characteristics. Finally, our study transcribed, coded and analysed what emerged directly from the consultation visit without the filter of questionnaires which could be biased by patients' desire to comply with their doctor or by false records.

The main limitation of the study is that it focuses on secondary analysis of previously collected data which were not specifically focused on occupational status. It means that we did not have detailed information available about work. As an example, our employed-patients sample included both employees and self-employed without the possibility to distinguish between them. Therefore, differentiating the two groups could be a future area of focus allowing to investigate whether different job conditions are related to specific information needs concerning work and psychosocial issues. Moreover, only half of the original samples gave details about the occupation. Therefore, it was not possible to stratify the sample according to the 
type of employment in the present paper. It has also to be considered that educational level may vary according to educational opportunities. For example, a difference can exist between a young woman born in the 70s and an older retired woman born in the 40s. In any case, we included education in the statistical model in order to take into account its impact on our primary outcome (number of questions asked). Finally, we did not collect the type of BC (ie, triple-negative), which may have somehow affected consultations. Despite that, according to our inclusion/ exclusion criteria, we recruited only women with a recent diagnosis of early-stage BC, specifically excluding the diagnosis of metastasis or disease relapse. Finally, we have characterised the sample in terms of cancer stages, taking into account such variable in our analyses.

\section{CONCLUSIONS}

To conclude, the ability to continue working and to remain active in the psychosocial context are important aspects of the quality of life as they mediate the effect of cancer and its treatment. Employment status was found to have an impact especially on the type of questions patients with early-stage $\mathrm{BC}$ asked and their information needs. In particular, the information needs of employed patients differ from those of non-employed or retired patients. Despite that, other variables like age and education level interrelate with employment status in determining the number of questions asked and should, therefore, be taken into account in profiling different subgroups of patients.

Acknowledgements We would like to thank all participating patients and their family members as well as all medical oncologists of the centres involved in the study. We also thank Dr Sara Cingarlini and Dr Valentina Zambonin of the University Hospital of Verona for their precious help in classifying patients' cancer stages.

Contributors MAM was involved in the conceptualisation, data analysis, interpretation, drafting/critical revision of the work, and approved the final manuscript. CP was involved in the interpretation, drafting/critical revision of the work, and approved the final manuscript. GD was involved in data curation and approved the final manuscript. AG was involved in the conceptualisation and approved the final manuscript. CB was involved in the conceptualisation and approved the final manuscript. $A B$ was involved in data curation, drafting of the work and approved the final manuscript. CG was involved in the conceptualisation, interpretation, drafting/critical revision of the work, and approved the final manuscript. LDP was involved in the supervision and critical revision of the work, and approved the final manuscript.

Funding The authors have not declared a specific grant for this research from any funding agency in the public, commercial or not-for-profit sectors.

Competing interests None declared.

Patient and public involvement Patients and/or the public were not involved in the design, or conduct, or reporting, or dissemination plans of this research.

Patient consent for publication Not required.

Ethics approval Ethics Committee of the Hospital Trust of Verona and the Provincial Ethics Committee of Brescia.

Provenance and peer review Not commissioned; externally peer reviewed.

Data availability statement Data are available upon reasonable request.

Open access This is an open access article distributed in accordance with the Creative Commons Attribution Non Commercial (CC BY-NC 4.0) license, which permits others to distribute, remix, adapt, build upon this work non-commercially, and license their derivative works on different terms, provided the original work is properly cited, appropriate credit is given, any changes made indicated, and the use is non-commercial. See: http://creativecommons.org/licenses/by-nc/4.0/.

ORCID iD

Cinzia Perlini http://orcid.org/0000-0002-4281-0920

\section{REFERENCES}

1 WHO, International Agency for Research and Cancer, GLOBOCAN. Cancer incidence andMortality worldwide in 2018, 2018. Available: http://globocan.iarc.fr/Pages/fact_sheets_cancer.aspx

2 I numeri del cancro in Italia 2019. Rapporto AIOM-AIRTUM, 2020. Available: http://www.salute.gov.it/portale/news/p3_2_1_1_1.jsp? lingua $=$ italiano\&menu=notizie\& $\mathrm{p}=$ dalministero\&id $=3897$

3 Mitchell T. The social and emotional toll of chemotherapy - patients' perspectives. Eur J Cancer Care 2007;16:39-47.

4 Bulotiene G, Veseliunas J, Ostapenko V, et al. Women with breast cancer: relationship between social factors involving anxiety and depression. Arch Psychiatry Psychotherapy 2008;4:57-62.

5 Ferrell BR, Grant MM, Funk B, et al. Quality of life in breast cancer survivors as identified by focus groups. Psychooncology 1997;6:13-23.

6 Friesen MN, Yassi A, Cooper J. Return-To-Work: the importance of human interactions and organizational structures. Work 2001;17:11-22.

7 Bowling A. What things are important in people's lives? A survey of the public's judgements to inform scales of health related quality of life. Soc Sci Med 1995;41:1447-62.

8 Kennedy F, Haslam C, Munir F, et al. Returning to work following cancer: a qualitative exploratory study into the experience of returning to work following cancer. Eur J Cancer Care 2007;16:17-25.

9 Rasmussen DM, Elverdam B. The meaning of work and working life after cancer: an interview study. Psychooncology 2008;17:1232-8.

10 Frazier LM, Miller VA, Horbelt DV, et al. Employment and quality of survivorship among women with cancer: domains not captured by quality of life instruments. Cancer Control 2009;16:57-65.

11 Johnsson A, Fornander T, Rutqvist LE, et al. Factors influencing return to work: a narrative study of women treated for breast cancer. Eur J Cancer Care 2010;19:317-23.

12 Brown RF, Owens M, Bradley C. Employee to employer communication skills: balancing cancer treatment and employment. Psychooncology 2013;22:426-33.

13 EURACS. Italy pension summary, 2020. Available: http://euracs.eu/ summaries/italy-pension-summary

14 Main DS, Nowels CT, Cavender TA, et al. A qualitative study of work and work return in cancer survivors. Psychooncology 2005;14:992-1004.

15 European Commission. Italy - Statutory sick pay, 2020. Available: https://ec.europa.eu/social/main.jsp?catld=1116\&langld=en\& intPageld $=4620$

16 European Commission. Italy - Unemployment benefits: NASpl and DIS-COLL, 2020. Available: https://ec.europa.eu/social/main.jsp? catld $=1116 \&$ langld $=$ en\&intPageld $=4627$

17 European Commission. Italy - Health services, 2020. Available: https://ec.europa.eu/social/main.jsp?langld=en\&catld=1116\& intPageld $=4619 \&$

18 Hack TF, Pickles T, Ruether JD, et al. Behind closed doors: systematic analysis of breast cancer consultation communication and predictors of satisfaction with communication. Psychooncology 2010;19:626-36.

19 Maunsell E, Brisson C, Dubois L, et al. Work problems after breast cancer: an exploratory qualitative study. Psychooncology 1999;8:467-73.

20 Davis RE, Koutantji M, Vincent CA. How willing are patients to question healthcare staff on issues related to the quality and safety of their healthcare? An exploratory study. Qual Saf Health Care 2008:17:90-6.

21 Ormandy P. Defining information need in health - assimilating complex theories derived from information science. Health Expect 2011;14:92-104.

22 Taylor S, Harley C, Campbell LJ, et al. Discussion of emotional and social impact of cancer during outpatient oncology consultations. Psychooncology 2011;20:242-51.

23 Ahn E, Cho J, Shin DW, et al. Impact of breast cancer diagnosis and treatment on work-related life and factors affecting them. Breast Cancer Res Treat 2009;116:609-16.

24 Nilsson M, Olsson M, Wennman-Larsen A, et al. Return to work after breast cancer: women's experiences of encounters with different stakeholders. Eur J Oncol Nurs 2011;15:267-74. 
25 Tamminga SJ, de Boer AGEM, Verbeek JHAM, et al. Breast cancer survivors' views of factors that influence the return-towork process--a qualitative study. Scand J Work Environ Health 2012;38:144-54.

26 Timperi AW, Ergas IJ, Rehkopf DH, et al. Employment status and quality of life in recently diagnosed breast cancer survivors. Psychooncology 2013;22:1411-20.

27 Barnes AJ, Robert N, Bradley CJ. Job attributes, job satisfaction and the return to health after breast cancer diagnosis and treatment. Psychooncology 2014;23:158-64.

28 Musti MA, Collina N, Stivanello E, et al. Perceived work ability at return to work in women treated for breast cancer: a questionnairebased study. Med Lav 2018;109:407-19.

29 Cocchiara RA, Sciarra I, D'Egidio V, et al. Returning to work after breast cancer: a systematic review of reviews. Work 2018;61:463-76.

30 Tavan H, Azadi A, Veisani Y. Return to work in cancer patients: a systematic review and meta-analysis. Indian J Palliat Care 2019;25:147-52.

31 Braybrooke JP, Mimoun S, Zarca D, et al. Patients' experiences following breast cancer treatment: an exploratory survey of personal and work experiences of breast cancer patients from three European countries. Eur J Cancer Care 2015;24:650-61.

32 Arfi A, Baffert S, Soilly A-L, et al. Determinants of return at work of breast cancer patients: results from the OPTISOINS01 French prospective study. BMJ Open 2018;8:e020276.

33 Söderman M, Friberg E, Alexanderson K, et al. Women's experiences of encounters with healthcare professionals' regarding work after breast-cancer surgery and associations with sickness absence: a 2-year follow-up cohort study. Support Care Cancer 2019;27:1197-206.

34 Takahashi M, Tsuchiya M, Horio Y, et al. Job resignation after cancer diagnosis among working survivors in Japan: timing, reasons and change of information needs over time. Jpn J Clin Oncol 2018;48:43-51.

35 Tamura S, Sakaguchi K, Yamanaka R. Concerns and returns to work in patients with breast cancer receiving outpatient chemotherapy: a pilot study. Asia Pac J Oncol Nurs 2019;6:187-92.

36 Siminoff LA, Ravdin P, Colabianchi N, et al. Doctor-Patient communication patterns in breast cancer adjuvant therapy discussions. Health Expect 2000;3:26-36.

37 Maunsell E, Drolet M, Brisson J, et al. Work situation after breast cancer: results from a population-based study. J Nat/ Cancer Inst 2004;96:1813-22.

38 Goss C, Ghilardi A, Deledda G, et al. INvolvement of breast CAncer patients during oncological consultations: a multicentre randomised controlled trial--the INCA study protocol. BMJ Open 2013;3:e002266.

39 Goss C, Deledda G, Bottacini A, et al. Information needs of female Italian breast cancer patients during their first oncological consultation. Eur J Oncol Nurs 2015;19:451-7.

40 Bottacini A, Goss C, Mazzi MA, et al. The involvement of early stage breast cancer patients during oncology consultations in Italy: a multi-centred, randomized controlled trial of a question prompt sheet versus question listing. BMJ Open 2017;7:e015079.

41 Jenkins V, Fallowfield L, Saul J. Information needs of patients with cancer: results from a large study in UK cancer centres. $\mathrm{Br} J$ Cancer 2001;84:48-51.
42 Brown RF, Butow PN, Dunn SM, et al. Promoting patient participation and shortening cancer consultations: a randomised trial. Br J Cancer 2001;85:1273-9.

43 Fagerlind H, Lindblad AK, Bergström I, et al. Patient-Physician communication during oncology consultations. Psychooncology 2008;17:975-85.

44 Hamilton LC. Regression with graphics: a second course in applied statistics. Belmont, CA: Wadsworth Inc, 1992.

45 StataCorp. Stata statistical software: release 14. College Station, TX: StataCorp LP, 2015.

46 von Elm E, Altman DG, Egger M, et al. The strengthening the reporting of observational studies in epidemiology (STROBE) statement. Epidemiology 2007;18:800-4.

47 Amin MB, Edge S, Greene F, et al. Ajcc cancer staging manual. Eight edition. Springer International Publishing, 2017.

48 Taskila T, Lindbohm ML. Factors affecting cancer survivors' employment and work ability. Acta Oncol 2007;46:446-51.

49 Mock V. Breast cancer and fatigue: issues for the workplace. Aaohn $J$ 1998;46:425-31.

50 Wallberg B, Michelson $\mathrm{H}$, Nystedt $\mathrm{M}$, et al. Information needs and preferences for participation in treatment decisions among Swedish breast cancer patients. Acta Oncol 2000;39:467-46.

51 Eggly S, Penner LA, Greene M, et al. Information seeking during "bad news" oncology interactions: Question asking by patients and their companions. Soc Sci Med 2006;63:2974-85.

52 Street RL, Gordon HS. Companion participation in cancer consultations. Psychooncology 2008;17:244-51.

53 Mazer BL, Cameron RA, DeLuca JM, et al. "Speaking-for" and "speaking-as": pseudo-surrogacy in physician-patient-companion medical encounters about advanced cancer. Patient Educ Couns 2014;96:36-42.

54 Gilbar R, Barnoy S. Companions or patients? the impact of family presence in genetic consultations for inherited breast cancer: relational autonomy in practice. Bioethics 2018;32:378-87.

55 Lindbohm M-L, Kuosma E, Taskila T, et al. Early retirement and nonemployment after breast cancer. Psychooncology 2014;23:634-41.

56 Butow P, Laidsaar-Powell R, Konings S, et al. Return to work after a cancer diagnosis: a meta-review of reviews and a meta-synthesis of recent qualitative studies. J Cancer Surviv 2020;14:114-34.

57 Del Piccolo L, Mazzi MA, Mascanzoni A, et al. Factors related to the expression of emotions by early-stage breast cancer patients. Patient Educ Couns 2019;102:1767-73.

58 Del Piccolo L, Mazzi MA, Scardoni S, et al. A theory based proposal to evaluate patient-centred communication in medical consultations: the Verona patient-centred communication evaluation scale (VRCOPE). Health Educ 2008;108:355-72.

59 Costantini A, Grassi L, Picardi A, et al. Awareness of cancer, satisfaction with care, emotional distress, and adjustment to illness: an Italian multicenter study. Psychooncology 2015;24:1088-96.

60 Sheehy EM, Lehane E, Quinn E, et al. Information needs of patients with breast cancer at years one, three, and five after diagnosis. Clin Breast Cancer 2018;18:e1269-75.

61 Catt S, Starkings R, Shilling V, et al. Patient-Reported outcome measures of the impact of cancer on patients' everyday lives: a systematic review. J Cancer Surviv 2017;11:211-32.

62 Kamau C. Preparing patients with cancer who work and treatment responsiveness. BMJ Support Palliat Care 2017;7:94-7. 